\title{
As Interações Entre o Setor Saúde e a Saúde Mental a Partir das Estatísticas de Ciência e Tecnologia*
}

\author{
Catari Vilela Chaves \\ Cedeplar-UFMG e PUCMinas
}

Recebido: 19/6/2006 Aprovado: 25/10/2006

\section{RESUMO}

A partir da literatura de economia da tecnologia, este artigo enfoca a dimensão setorial do Sistema Nacional de Inovação (NSI, na sigla em inglês) com ênfase no setor saúde e sua conexão com a saúde mental. Com base nos indicadores tradicionais de Ciência e Tecnologia C\&T (artigos e patentes, respectivamente) aplica-se o método de clusters hierárquicos para investigar as características e distribuiçôes dos países. Identifica-se uma descontinuidade científico-tecnológica entre o grupo de países mais desenvolvidos e os menos desenvolvidos com relação ao setor saúde, indicando peculiaridades desse setor e possíveis problemas específicos para catching up. O Brasil apresenta produção científica e tecnológica em saúde, mas apenas produção científica em saúde mental. Espera-se que o País aproveite seu potencial científico e avance no sentido de incentivar o setor produtivo na área.

\footnotetext{
Agradeço aos três pareceristas anônimos da Revista Brasileira de Inovação. A responsabilidade pelos erros é inteiramente da autora.
} 
PalaVRas-Chave | Economia e Saúde; Economia e Saúde Mental; Análise de Cluster; Sistema de Inovação em Saúde

CÓDIGOS JEL $\quad$ O30; I10

\section{ABSTRACT}

This article focuses the sectoral dimension of the national systems of innovation (NSI), highlighting the health innovation system and its connection with mental health. On the basis of traditional science and technology (S\&T) indicators - articles and patents, respectively - the hierarchical clusters approach is used to investigate countries characteristics and distributions. Considerable discontinuity in the health sector is noticed regarding scientific and technological productions between developed and developing countries, evidencing problems that developing countries need to overcome in order to catch up. Brazil has a balanced scientific and technological production in health but only scientific production in mental health. It is expected that the country takes advantage of its scientific potential and move forward to encourage the productive sector in the field.

KeYWORDS I Economics and Health; Economics and Mental Health; Cluster Analysis; Health Innovation System

JEL-CODES $\mid$ O30;I10.

\section{Introdução}

O objetivo deste artigo é identificar a posição da saúde mental no interior do sistema de inovação setorial em saúde. Para atingir este objetivo são necessárias duas etapas, uma qualitativa e outra quantitativa. Em primeiro lugar, sob o ponto de vista teórico, a questão básica é saber se é adequado ou 
não a utilização do termo sistema subsetorial de inovação em saúde mental. A bibliografia consultada sugere que não, mantendo-se a discussão da saúde mental no interior do sistema de inovação setorial em saúde. Em segundo lugar, por meio de estatísticas de artigos e patentes, é possível construir uma tipologia de países para investigar quantitativamente suas características e distribuições. Pela análise de clusters hierárquicos, os países são agrupados de acordo com os regimes de interação a que pertencem. A incursão quantitativa permite identificar diferenças importantes entre a posição de países considerando-se isoladamente o setor saúde. Seguindo a mesma lógica, a discussão sobre a saúde mental pôde ser iniciada. Duas bases de dados distintas e duas tipologias de países são construídas, por métodos clusters hierárquicos e Grade of Membership. Os resultados encontrados em ambas metodologias convergem e apontam características semelhantes entre os grupos de países.

$\mathrm{Na}$ classe de doenças não-transmissíveis, as condições neuropsiquiátricas têm sido foco de debates internacionais em saúde e, especificamente, na área de economia e saúde mental. O tema tem sido pouco abordado na literatura econômica brasileira. Assim, torna-se bastante oportuno refletir sobre saúde mental e suas conexões com o sistema de inovação setorial em saúde observando seu perfil internacional.

Este artigo está dividido em quatro seções, além da introdução. A segunda apresenta os fundamentos teóricos sobre NSI, sistema de inovação em saúde e algumas características da saúde mental. A terceira refere-se à metodologia, descrevendo as bases de dados sobre produção científica e produção tecnológica, e ao método de análise multivariada de clusters hierárquicos. A quarta descreve os resultados e a quinta apresenta as principais conclusōes do artigo.

\section{Aspectos teóricos}

O conceito de Sistema Nacional de Inovação (NSI) é "certamente é uma idéia fundadora" (Albuquerque, 2004:3) e será utilizado para organizar a discussão teórica deste artigo.

Para Rosenberg (1982), em termos conceituais, a tecnologia pode ser definida como um conjunto de conhecimentos sobre certas classes de eventos e atividades. Representa o conhecimento de técnicas, métodos e design que apresentam determinadas conseqüências, mesmo de causas desconhecidas. Não é, 
portanto, um tipo fundamental de conhecimento, mas uma forma de conhecimento que tem gerado certa taxa de progresso econômico por centenas de anos. Isso significa que muitas atividades produtivas são executadas sem um conhecimento científico prévio de seu funcionamento. Tanto no passado quanto no presente, o conhecimento tecnológico pode ser anterior ao científico. $\mathrm{O}$ desenvolvimento tecnológico tem um papel muito importante para a subseqüente agenda científica, indicando sua direção e potenciais de desenvolvimento.

Em excelente contribuição para a área de economia da ciência e tecnologia, Rosenberg (1990) investiga os motivos que levam as firmas a investirem em pesquisa. Sua principal conclusão é a de que as interações e feedbacks entre C\&T são tão fortes que as firmas passam a investir em ciência básica como forma de participar de uma rede de informações mais ampla. Na verdade, a maneira que as firmas encontram de permanecerem ligadas a essa rede é realizando pesquisa. A pesquisa básica é fundamental para monitorar e avaliar o desenvolvimento científico e tecnológico realizado fora da firma. Ainda que uma parcela expressiva das pesquisas seja feita nas universidades, as firmas necessitam de uma equipe de pesquisadores internos para, no mínimo, absorverem o conhecimento gerado em outros centros.

O conhecimento produzido é posto na estante, não possui custos e é acessivel a todos os entrantes, desde que já tenha sido produzido, dizem os economistas. Mas esse modelo é falho, porque freqüentemente se requer capacidade de pesquisa substancial para entender, interpretar e avaliar o conhecimento que foi colocado na estante. (Rosenberg, 1990:171)

De acordo com Freeman (1995), o NSI é um arranjo institucional que envolve diversos componentes, como firmas e seus departamentos de P\&D, universidades e institutos de pesquisas, instituições de educação, sistema financeiro, setor governamental, etc., criando uma rede de informações que objetiva impulsionar o desenvolvimento tecnológico em áreas específicas. "Esses componentes interagem entre si, articulam-se e possuem diversos mecanismos que iniciam processos de ciclos virtuosos" (Albuquerque, 2004:4). ${ }^{1}$

\footnotetext{
Albuquerque (2004) apresenta de forma brilhante a evolução histórica e as principais referências bibliográficas sobre o conceito de NSI.
} 
Entre as principais fontes para o desenvolvimento de oportunidades tecnológicas destaca-se o conhecimento científico, ainda que a relação entre ciência e tecnologia seja complexa, com grandes lags temporais e feedbacks complicados. Como exemplo, muitos avanços recentes em biotecnologia estão diretamente vinculados ao desenvolvimento em ciências básicas. Entre 198384, pesquisadores da Yale University encontraram resultados muito interessantes, dando suporte à hipótese de que o conhecimento científico e as universidades exercem papel importante para o progresso tecnológico, principalmente no caso de ciências básicas (Biologia, Química, Matemática e Física). Parcela substancial das pesquisas na área médica é realizada em universidades. Os autores encontraram forte ligação entre o desenvolvimento científico e a presença das universidades nas pesquisas, sendo que as indústrias com tecnologia baseada em ciências biológicas são alimentadas principalmente por novos desenvolvimentos científicos, o que não é tão usual em outras áreas (Klevorick et al., 1995).

Por muitos séculos o desenvolvimento tecnológico foi essencialmente empírico, baseado em simulações tipo "tentativa e erro", com limitada fundamentação no conhecimento científico. Essa relação foi se alterando ao longo dos séculos e, atualmente, ciência e tecnologia tornaram-se verdadeiramente interdependentes. Isso pode ser demonstrado pelo rápido desenvolvimento da tecnologia industrial relacionada aos avanços científicos em áreas como mecânica, eletrodinâmica e química, assim como pela expansão das instituições profissionais de pesquisa e desenvolvimento. Em medicina, as estruturas institucionais têm tido papel importante no que diz respeito à transferência de conhecimentos científicos para a prática clínica. Nesse sentido, as interaçôes entre indústria, universidade e governo têm sido fundamentais para a descoberta de novos medicamentos (Gelijns, 1990).

Segundo Nelson (2003), o avanço tecnológico é um processo evolucionário. Em qualquer momento, existem técnicas e teorias alternativas competindo entre si e a disputa de qual será efetivamente aceita é uma questão de seleção ex post. A experiência é essencial para avaliar as incertezas relacionadas à introdução de novos produtos ou procedimentos, especialmente em Medicina. No entanto, aceitar esta proposição não significa desmerecer a importância da teoria, amplamente definida como guia nos esforços para avançar, nem 
negar a relevância das pesquisas recentes que ocorrem nos laboratórios. Prática clínica e teoria co-evoluem e se revezam na liderança.

O conceito de inovação é importante para esclarecer o papel dos investimentos intangíveis bem como sua diversidade. Em termos gerais, as características dos fluxos de informação em ciência e tecnologia para o setor saúde nos países desenvolvidos envolvem o complexo médico-industrial, o sistema biomédico de inovação (contribuição dos hospitais para a produção científica) e a interação entre universidades e indústrias para a geração de tecnologia médica. Essas características requerem um sistema de inovação bem desenvolvido e instituições de bem-estar abrangentes (Albuquerque \& Cassiolato, 2002). A partir dessa exposição, os autores apontam algumas especificidades do sistema de inovação em saúde, ${ }^{2}$ cruciais para a formação de uma proposta preliminar de inserção da saúde mental no interior do sistema de inovação em saúde. Entre as características da atenção à saúde mental, destacam-se:

(i) de forma semelhante à saúde em geral, o papel das universidades e das instituições de pesquisa na geração de conhecimento e novas tecnologias é extremamente importante para dinamizar o fluxo de informaçôes, tanto para as indústrias (principalmente farmacêutica e de biotecnologia), quanto para o governo. Acrescente-se que a formação dos profissionais da área ao nível de graduação e de pós-graduação ocorre nas universidades (Albuquerque \& Cassiolato, 2000);

(ii) em termos da saúde mental, a integração entre universidade, hospital e laboratório é fundamental para as pesquisas e informações em C\&T;

(iii) as inter-relações entre universidades e saúde pública são cruciais para a elaboração de propostas de regulamentação da saúde mental;

(iv) o ideal é que a rede de profissionais envolvidos na área (médicos, enfermeiros, psicólogos, assistentes sociais, etc.) possa suprir as equipes da saúde pública com feedback relevante sobre a efetividade dos novos tratamentos, visando a melhoria da qualidade de vida dos portadores de sofrimento mental;

(v) a exigência de testes relativos a toxicidade dos novos agentes pelas agências de regulação, como a Food and Drugs Administration (FDA) nos Estados Unidos, para monitorar a eficácia e a segurança dos medicamentos neuropsiquiátricos (Gelijns, 1990);

2 É importante ressaltar que são poucos os trabalhos na área de sistema de inovação em saúde. 
(vi) vontade política, um trabalho integrado entre as esferas governamentais federal, estadual e municipal juntamente com a equipe de tratamento, para promover o fluxo de informações necessário em meio à complexa área da saúde mental. Nesse sentido, o conceito de tecnologia social, relacionado à divisão do trabalho, à coordenação e ao gerenciamento das tarefas (Nelson, 2003), pode ser útil para se realizar a conexão entre as áreas prestadoras de serviços afins e bem-estar social.

A estrutura acima refere-se ao NSI de países desenvolvidos. A hipótese básica deste artigo é que, mesmo em países avançados, a atenção à saúde mental é pouco articulada, se comparada à organização do sistema de inovação em saúde. Essa menor articulação pode ser conseqüência da complexidade científica do tema. Dessa conjectura inicial deriva uma segunda, relativa aos países em desenvolvimento, que sugere a existência de maiores problemas estruturais na saúde mental em relação ao problemático e incompleto sistema setorial de inovação no setor saúde em geral. Nos países em desenvolvimento, os principais pontos de estrangulamento enfrentados pela saúde mental são a ausência de produção sistemática em ciência e tecnologia, a falta de condições e/ou recursos de treinamento adequado para os trabalhadores da área e, principalmente, a falta de instalaçóes e recursos adequados para tratamento de portadores de transtornos mentais severos (Chaves, 2005).

A discussão sobre sistema de inovação envolve, por um lado, a teoria sobre o papel da ciência e da tecnologia e, por outro, a teoria da demanda de mercado. "Interação entre o sistema de P\&D e as atividades produtivas e o mercado é indicada como decisiva, sugerindo um papel estratégico dos feedbacks entre essas duas dimensões" (Albuquerque, 2004:5).

O papel do conhecimento científico é bem definido no tocante à efetivação do desenvolvimento tecnológico em saúde. No entanto, o mesmo não pode ser afirmado sobre o papel da demanda de mercado. Segundo Arrow (1971), dadas as especificidades econômicas na área de atenção médica, pode-se supor que a dinâmica de inovação do setor saúde deva seguir uma lógica distinta da lógica de outros setores econômicos. "A noção de 'mercado' em saúde é diferente do conceito de mercado para outros setores da economia onde, em princípio, os consumidores sabem (...) o que comprar" (Gelijns, 1990:150). Entre as principais diferenças consideradas pelos autores, destacam-se: 
(i) a suposição de que os consumidores têm conhecimento de mercado em geral e que suas escolhas sejam autônomas. No caso da saúde, essas hipóteses são bem mais limitadas, pois são os profissionais (no caso, os médicos) que decidem o tipo de tratamento e demais intervençōes necessárias;

(ii) a constante presença do risco, porque os efeitos colaterais adversos da tecnologia médica afetam a vida, a concepção e o nascimento, o corpo, a mente, etc. Durante a fase de desenvolvimento de novas tecnologias, os benefícios ou riscos são altamente incertos, motivo pelo qual as novas tecnologias são, em geral, aprimoradas após avaliações clínicas;

(iii) a necessidade de contenção de custos, principalmente quando o pagamento dos profissionais da área é realizado por terceiros e não pelos pacientes, quando estes possuem seguro total.

Esses são alguns dos motivos que tornam fundamental a presença do governo no mercado de saúde para regulamentá-lo, tanto para garantir a qualidade dos produtos quanto a adequação de seus custos.

\section{Metodologia}

\subsection{Bases de dados}

\subsubsection{Indicadores de produção científica}

Os dados sobre artigos científicos foram fornecidos pelo Ministério da Ciência e Tecnologia (MCT) a partir da base do Institute for Scientific Information (ISI), composto pelo Science Citation Index Expanded (SCI), Social Sciences Citation Index (SSCI) e Arts \& Humanities Citation Index (A\&HCI). São utilizados como proxies da produção científica.

Para analisar a infra-estrutura científica por país, serão utilizadas todas as disciplinas referentes ao sistema nacional de inovação (NSI), as disciplinas que se relacionam ao setor saúde e as que se relacionam à saúde mental. Das 104 disciplinas enumeradas pelo ISI, ${ }^{3} 47$ são relacionadas à saúde e cinco diretamente relacionadas à saúde mental, ${ }^{4}$ pois não é possível separar os artigos

3 A lista de disciplinas científicas encontra-se no Anexo, Quadro 1.A.

4 As disciplinas relacionadas à saúde mental são: Neurologia; Neurociência e Comportamento; Psiquiatria; Psicologia; Clínica em Psiquiatria e Psicologia. 
sobre saúde mental publicados nas disciplinas Farmacologia e Farmácia, Biologia Molecular e Genética, etc. As informações estão disponíveis para 118 países em 2001.

Existem vantagens e desvantagens na utilização de artigos como indicadores de infra-estrutura científica. A discussão sobre o significado das estatísticas publicadas pelo ISI será sintetizada a seguir.

Em primeiro lugar, nem toda a produção científica é indexada pelo ISI. Há um elevado padrão de exigência para uma revista ser indexada. $\mathrm{Na}$ área de economia, por exemplo, é bem mais fácil uma revista acadêmica ser incluída no prestigioso EconLit do que no ISI.

Em segundo lugar, a mera contagem de artigos certamente não capta as diferentes contribuições científicas que representam. Por isso, um artigo que representa uma importante ruptura científica conta tanto quanto um artigo que apresenta apenas uma contribuição incremental. Para superar esse viés é comum utilizar estatísticas de citações de artigos. Entretanto, essas últimas também apresentam problemas, em especial diminuindo razoavelmente a participação de países menos desenvolvidos no cenário mundial. Por isso, este artigo utiliza a contagem de artigos como base das estatísticas.

Em terceiro lugar, o forte viés lingüístico das estatísticas do ISI (Sandelin $\&$ Sarafoglou, 2004) favorece a produção científica de países de língua inglesa em detrimento dos demais países.

Em quarto lugar, a produção científica não se expressa apenas na produção de artigos. Eventos como conferências, congressos, debates e outros são importantes e, para a interação com o setor produtivo, são destacadas fontes de informações sobre fluxos tecnológicos (IBGE, 2002).

Contudo, a base do ISI oferece uma rica contribuição: longas séries estatísticas, comparabilidade internacional, desagregação por disciplinas, identificação institucional dos autores e suas instituições (possibilitando a localização geográfica da atividade) e fácil acesso (disponível em www.isiknowledge.com).

\subsubsection{Indicadores de produção tecnológica}

Uma patente é um documento registrado por uma agência governamental autorizada, garantindo o direito de excluir terceiros da produção ou uso de uma nova invenção específica por um determinado número de anos. A garantia é 
dada ao criador da invenção ou processo após o exame que focaliza tanto a novidade do item quanto seu potencial de utilidade. $\mathrm{O}$ direito da patente pode ser assinado pelo inventor ou por outra pessoa (usualmente o empregador, que pode ser uma corporação) e/ou vendido/licenciado para uso de terceiros. $\mathrm{O}$ propósito do sistema de patentes é encorajar invençôes e progresso técnico, conferindo poder de monopólio temporário ao inventor (Griliches, 1990).

O documento das patentes (solicitadas e concedidas) encontradas no site do United States Patent and Trademark Office (USPTO) contém as informações utilizadas para a elaboração das bases de dados. Entre essas informações está a classe tecnológica da patente. Existe uma classificação internacional de patentes, preparada pela Organização Mundial de Propriedade Intelectual (OMPI, cujo site é www.wipo.org), ${ }^{5}$ que possui diversos níveis de desagregação: seçōes, subseções, classes e subclasses. São oito seções e mais de 600 subclasses. Se, por um lado, a alta desagregação das subclasses dificulta a análise por separar tecnologias relacionadas, por outro lado, a forma como a agregação é feita nos níveis de seção e subseção tem a finalidade de atender às necessidades dos escritórios de patentes e não de viabilizar análises acadêmicas no campo da economia da ciência e tecnologia.

Para superar esses problemas, uma iniciativa do Observatoire des Sciences et des Techniques (OST, 2000) propôs uma forma de agregação em seis domínios tecnológicos e em 30 subdomínios tecnológicos. O trabalho proposto pelo OST parte da classificação internacional da Organização Mundial de Propriedade Intelectual, mas os agrega, com o auxílio de especialistas das diversas áreas, de forma a viabilizar informaçōes para o formulador de políticas e para o analista da área de economia da tecnologia. $\mathrm{O}$ algoritmo da agregação, proposto pelo OST e que pode ser encontrado em publicação da entidade (OST, 2004:513-514), é reproduzido na Tabela 1.A, do Anexo.

A classificação das patentes por domínios e subdomínios tecnológicos, por exemplo, oferece uma visão clara sobre o setor a que pertence a patente. O levantamento de dados sobre patentes para o setor saúde incluirá os subdomínios tecnológicos relativos à engenharia médica, química orgânica, química macromolecular, produtos farmacêutico-cosméticos e biotecnologia. Com essa classificação, uma das maiores lacunas dos estudos que utilizam

5 WIPO em inglês é a sigla de World Intellectual Property Organization. 
estatísticas de patentes pôde ser contornada. Isso é especialmente importante para estudos da área de saúde.

A pesquisa sobre patentes foi feita por país do inventor e os dados estão disponíveis no endereço www.uspto.gov. A expressão de busca para a saúde inclui os subdomínios tecnológicos citados acima ${ }^{6}$ para 118 países em 2001. Para a saúde mental, a expressão de busca foi similar à realizada para a saúde, mas inclui palavras-chave sobre o nome de algumas doenças do sistema nervoso central - depressão, esquizofrenia, epilepsia, demência, doença de Parkinson, esclerose múltipla, doença de Alzheimer e enxaqueca. ${ }^{7}$

Resumindo, em relação aos indicadores de C\&T, justifica-se neste trabalho o uso de artigos publicados e de patentes, em vez de indicadores derivados de artigos e patentes, uma vez que a observação simultânea dessas variáveis é importante para análise das conexões entre C\&T e para formulação de modelos sobre processos inovativos (Schmoch, 1997).

\subsection{Método de análise}

O objetivo da análise de cluster é agrupar vários objetos em classes, de forma que objetos similares pertençam a uma mesma classe. $\mathrm{O}$ método de classificação hierárquica foi utilizado para produzir uma tipologia de países para o NSI e para o NSI em saúde e em saúde mental, gerando resultados satisfatórios e consistentes. Por meio desse instrumental analítico, foi possível analisar a

6 Expressão de busca no USPTO para saúde:

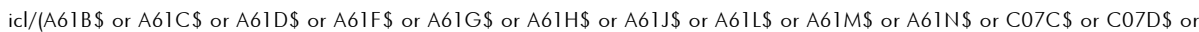

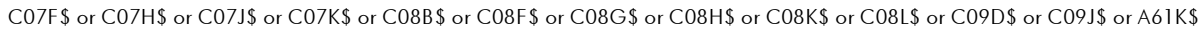
or C07G $\$$ or $\mathrm{Cl} 2 \mathrm{M} \$$ or $\mathrm{Cl} 2 \mathrm{~N} \$$ or $\mathrm{Cl} 2 \mathrm{P} \$$ or $\mathrm{Cl} 2 \mathrm{Q} \$$ or $\mathrm{Cl} 2 \mathrm{~S} \$$ ) and icn/(au) and isd/01/01/1981->12/31/1981.

A sigla icl refere-se à classificação internacional de patentes, icn é o país do inventor (no exemplo acima, AU é a sigla da Austrália) e isd é a data da publicação. A pesquisa foi realizada para 1981, 1991 e 2001 . Para os Estados Unidos, as patentes são fornecidas por estados, razão pela qual a sigla is (estado do inventor) foi utilizada junto com as siglas dos diversos estados norte-americanos, no lugar de icn. O levantamento desses dados foi realizado ao longo dos meses de dezembro de 2003, fevereiro e março de 2004.

7 Expressão de busca no USPTO para saúde mental:

Na pesquisa sobre saúde mental, foram incluídas as palavras-chave "nome das doenças" no título das patentes, no resumo e no objetivo. Dessa forma, foi possível restringir a relação da patente com a doença específica. Tomando a esquizofrenia como exemplo, a expressão de busca foi:

(Htl/schizophrenia or abst/schizophrenia or aclm/schizophrenia) and icl/(A61B $\$$ or A61C $\$$ or A61D $\$$ or A61F $\$$ or A61G $\$$ or A61 $\$$ or $\mathrm{A} 61 \mathrm{~J} \$$ or $\mathrm{A} 61 \mathrm{~L} \$$ or $\mathrm{A} 61 \mathrm{M} \$$ or $\mathrm{A} 61 \mathrm{~N} \$$ or $\mathrm{C} 07 \mathrm{C} \$$ or $\mathrm{C} 07 \mathrm{D} \$$ or $\mathrm{C} 07 \mathrm{~F} \$$ or $\mathrm{C} 07 \mathrm{H} \$$ or C07J $\$$ or C07K $\$$ or C08B $\$$ or C08F $\$$ or C08G $\$$ or $\mathrm{C} 08 \mathrm{H} \$$ or $\mathrm{C} 08 \mathrm{~K} \$$ or C08L $\$$ or C09D $\$$ or C09J\$ or $A 61 \mathrm{~K} \$$ or C07G $\$$ or C12M\$ or C12N\$ or C12P\$ or C12Q\$ or C12S\$) and icn/(AU) and isd/01/01/1991->12/31/1991

A sigla $\mathrm{Hl}$ é a abreviatura de título da patente, abst é o abstract ou resumo, aclm é o objetivo. O levantamento dos dados para 1981, 1991 e 2001 foi realizado ao longo dos meses de dezembro de 2003, fevereiro e março de 2004. 
produção científica e tecnológica do sistema de inovação no setor saúde e comparar os resultados com o do sistema de inovação. A mesma técnica foi utilizada para analisar a inserção da saúde mental no interior do sistema de inovação em saúde. O método, também conhecido como Hard Cluster Analysis, "utiliza-se do conceito de conjuntos clássicos (crisp sets) caracterizados pela inequivocidade de sua função de pertinência (ou pertencimento). Intuitivamente, a teoria dos conjuntos traz consigo uma noção dicotômica fundamental: pertencer ou não pertencer" (Simões, 2003:8).

Bernardes e Albuquerque (2003) identificaram três grupos de países com características semelhantes a partir das estatísticas de artigos e patentes, amplamente utilizadas na literatura como proxies de ciência e tecnologia para o sistema nacional de inovação.

Segundo os autores, os países menos desenvolvidos não produzem artigos e/ou patentes e, praticamente, não há articulação entre as esferas científica e tecnológica. Isso significa que o setor produtivo não se beneficia dos avanços científicos. Em termos de C\&T, apenas a produção científica contribui para o crescimento econômico. Este depende de outros fatores, como trabalho, disponibilidade de matérias-primas, condições de saúde da população, distribuição de renda, etc. Os países que se enquadram nessa categoria são classificados como pertencentes ao regime I.

Para os países em desenvolvimento, artigos e patentes são produzidos de forma sistemática, mas as interações entre $C \& T$ ainda não estão totalmente consolidadas. No entanto, pode-se perceber contribuições da produção científica e da tecnológica para o processo de crescimento econômico. Os países que possuem essas características pertencem ao regime II.

Finalmente, os países desenvolvidos possuem infra-estrutura científica e tecnológica bem consolidada, existem mecanismos de feedback entre ambas as dimensões e interações entre C\&T e a esfera econômica. Esses países pertencem ao regime III.

\subsubsection{Análise multivariada: clusters hierárquicos}

Segundo Everitt (1986) e Kaufman e Rousseeuw (1990), não há na literatura uma definição clara de cluster. Os conceitos são vagos, pois utilizam termos como similaridade, distância e semelhança, sem defini-los previamente. 
O consenso é de que não há uma definição única para cluster. Fica a critério do pesquisador a forma de avaliar e utilizar o termo cluster. Neste artigo adota-se a definição proposta por Everitt (1986:60): clusters são descritos como uma região contínua do espaço $p$ dimensional, que contém uma densidade relativamente grande de pontos, separada de outras regiões que contêm uma densidade relativamente menor de pontos.

Existem duas técnicas hierárquicas: a aglomerativa e a divisiva (ou de partição). Segundo Kaufman e Rousseeuw (1990):

Elas constróem sua hierarquia em direçōes opostas, possivelmente gerando resultados bem diferentes. (...) O método aglomerativo começa quando todos os objetos estão separados (isto é, no passo 0 temos n clusters). A cada passo dois clusters são unidos até que somente um seja gerado. Por outro lado, o método divisivo começa quando todos os objetos estiverem juntos (isto é, no passo 0 há um cluster) e a cada passo seguinte um cluster é dividido, até que haja n clusters. (p.44)

Neste artigo será utilizada a metodologia de clusters hierárquicos para encontrar uma tipologia entre países com relação à produção científica e tecnológica, expressa por artigos e patentes, respectivamente. Assim, será possível estabelecer os países que compóem os regimes II e III relativos ao setor saúde e comparar os resultados com os do sistema nacional de inovação proposto por Silva (2003).

Em alguns casos, a unidade de medida das variáveis pode alterar sensivelmente os resultados da estrutura do cluster. Por isso, os dados devem ser padronizados (Everitt, 1986; Kaufman \& Rousseeu, 1990). Essa padronização é feita através da média e do desvio médio absoluto:

$$
Z_{i k}=\frac{X_{i k}-\bar{X}_{k}}{\sigma_{k}}
$$

onde: $\mathrm{Z}_{\mathrm{ik}}$ é o valor normalizado de $\mathrm{X}_{\mathrm{ik}}$ que, por construção, tem média zero e desvio 1;

$\overline{\mathrm{X}}_{\mathrm{k}}$ é a média e $\sigma_{\mathrm{k}}$ o desvio das variáveis;

$\mathrm{k}$ representa as variáveis do modelo, expressas por artigos e patentes; i varia de 1 até $n$, sendo $n$ o número de países. 
Os dados da análise de cluster são organizados em termos de $p$ variáveis e $n$ objetos. No método aglomerativo hierárquico, procura-se converter os dados brutos por meio de uma medida de distância, após a padronização, gerando-se uma matriz de distâncias. A medida mais comum é a distância euclidiana, dada por:

$$
d_{i j}=\sqrt{\sum_{k=1}^{p}\left(X_{i k}-X_{j k}\right)^{2}}
$$

onde: $\mathrm{X}_{\mathrm{ik}}$ é o valor da k-ésima variável para o i-ésimo objeto.

Finalmente, a questão da determinação do número ótimo de clusters não possui uma solução formal definitiva. Segundo Everitt (1986:66), “o problema de determinar o número de clusters mais apropriado para um conjunto de dados pode ser difícil. Apesar dos numerosos debates na literatura, deve ser dito que nenhuma solução completamente satisfatória está disponível”. Neste trabalho foi estabelecido que oito é o número ideal de clusters. Com um número superior a oito, países do regime II em saúde como Taiwan, caracterizado por ter especialização em engenharia e atividades industriais, ficariam fora do cluster 1 , juntamente com os países do regime III, classificados como pertencentes a sistemas maduros com ênfase em saúde. ${ }^{8}$

\section{Resultados}

O conceito de limiar de produção científica é utilizado por Bernardes e Albuquerque (2003) para estabelecer a fronteira entre os países pertencentes aos regimes II e III. Os países desenvolvidos, que já conseguiram formar massa crítica em termos de sua produção científica, situam-se acima do limiar, pois são mais eficientes que os países em desenvolvimento. Isso significa que os países do regime III possuem maior produção tecnológica, gerada a partir de sua infraestrutura científica, e que há mais conexões entre ciência, tecnologia e crescimento econômico, relativamente ao grupo de países que compóem o regime II.

8 Os clusters são apresentados no anexo, conforme Dendogramas 1.A e 1.B. Para a saúde geral, os países que compõem - cluster 1 englobam de Filipinas a Taiwan e pertencem ao regime II. Os países que estão fora do cluster 1, desde a França aos Estados Unidos, compõem o regime III. Raciocínio análogo, em termos de clusters e regimes de interação, aplica-se à saúde mental em termos de C\&T. 
GRÁFICO 1

Artigos por milhão de habitantes $\left(\mathrm{A}^{*}\right) \mathrm{X}$ patentes por milhão de habitantes $\left(\mathrm{P}^{*}\right)$ em 1998. Dois subconjuntos são representados por diferentes símbolos e duas funções potência ajustam os subconjuntos. (em escala logarítmica)

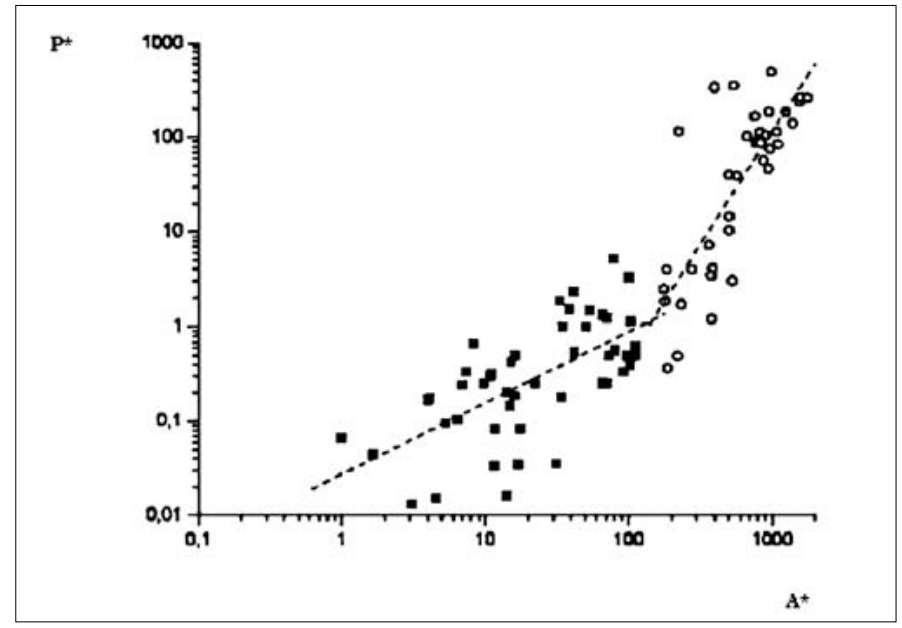

Fonte: Bernardes \& Albuquerque (2003).

Os autores ajustaram duas linhas compatíveis com duas regiões bem definidas graficamente. A interseção entre as duas linhas ocorre no ponto onde $\mathrm{A}^{*}$ era equivalente a 150 artigos per capita. Este foi considerado o "limiar" que identifica a transição do regime II para o III. O Gráfico 1 ilustra o limiar de produção científica para o conjunto de países que compóem o NSI.

A partir desse trabalho, Silva (2003) sugeriu a utilização da técnica de clusters hierárquicos para distinguir, com rigor, a fronteira entre os países componentes dos regimes II e III. Essa técnica é utilizada a partir das estatísticas de artigos e patentes. Naturalmente, os países pertencentes ao regime I não serão objeto da análise de cluster, pois sua característica principal é a ausência de produção sistemática em C\&T. Em linhas gerais, os países que integrarem o cluster 1 serão classificados como pertencentes ao regime II e os que estiverem fora do cluster 1 serão classificados como pertencentes ao regime III. A Tabela 1 apresenta os resultados da aplicação da técnica de cluster para o NSI.

Considerando o NSI em geral, 41 países fazem parte do regime I, 52 compõem o regime II e apenas 27 integram o regime III. 
GRÁFICO 2

Saúde geral - artigos e patentes (por milhão de habitantes) 2001

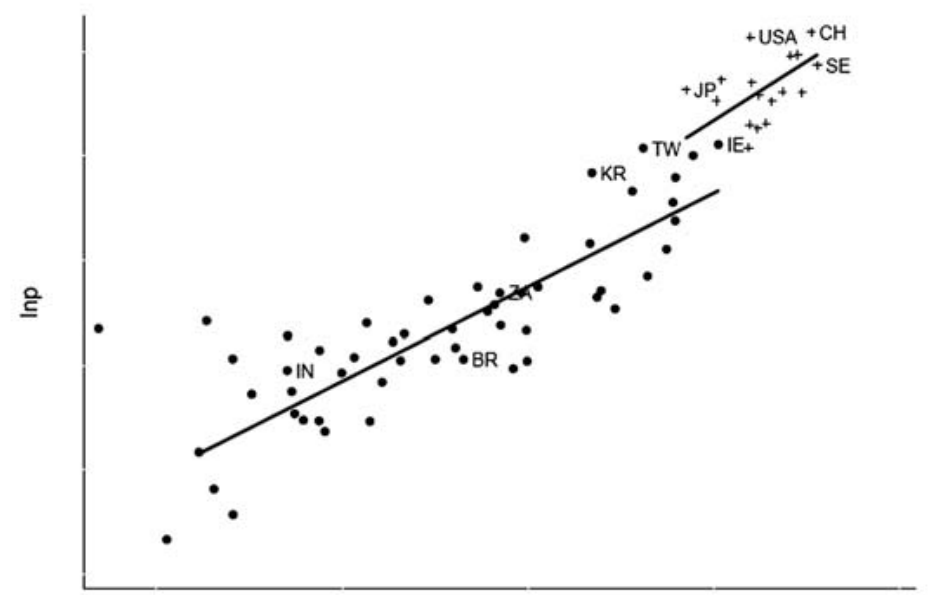

Ina

Fonte: ISI, USPTO, elaboração própria. As siglas de alguns países selecionados são dadas a seguir: IN - Índia; BR Brasil; ZA - África do Sul; KR - Coréia do Sul; TW - Taiwan; IE - Irlanda; JP - Japão; USA - Estados Unidos; CH Suiça; SE - Suécia.

Há mudanças importantes quando os dados da área de saúde são tratados isoladamente. Os resultados encontrados nesse artigo foram similares aos encontrados por Bernardes e Albuquerque (2003) e por Silva (2003) em termos da existência de limiares de produção científica para o NSI em saúde e para o NSI. A existência de um limiar de produção científica significa que os países conseguem obter massa crítica em termos científicos e, conseqüentemente, há maior articulação entre as esferas científica e tecnológica.

Dadas as características do setor saúde, o ponto central é avaliar o salto científico e tecnológico necessário para que os países do regime II possam ingressar no regime III. O Gráfico 2 permite visualizar essa questão. Em primeiro lugar, não foi detectada interseção entre os dois regimes e sim uma descontinuidade na produção científico-tecnológica entre ambos. Em segundo lugar, a trajetória das retas representativas dos regimes II e III não é convergente. Isso ilustra a dificuldade cada vez maior que os países do regime II enfrentarão para alcançar um estágio de desenvolvimento mais avançado, caso não haja investimentos em C\&T. 
TABELA 1

Países componentes do NSI por regime de interação - 2000

\begin{tabular}{lll}
\hline Regimes $\quad$ Países & Países por regime
\end{tabular}

Regime I

Regime II

Regime III

Alemanha, Austrália, Áustria, Bélgica, Canadá, Coréia do Sul, Dinamarca, Eslovênia, Espanha, Estados Unidos, Finlândia, França, Holanda, Hong Kong, Irlanda, Islândia, Israel, Itália, Japão, Luxemburgo, Noruega, Nova Zelândia, Reino Unido, Singapura, Suécia, Suiça, Taiwan

41

Bósnia e Herzegovina, Camarões, Chade, El Salvador, Equador, Gana, Geórgia, Guiana, Haiti, Irã, Jordânia, Lituânia, Macedônia, Madagascar, Malawi, Mali, Maurício, Mauritânia, Moldávia, Nova Caledônia, Papua-Nova Guiné, Paraguai, Polinésia Francesa, São Vicente e Granadinas, São Vicente e Granadinas, Senegal, Suazilândia, Sudão, Suriname, Tajiquistão, Trindade e Tobago, Tunísia, Turquemenistão, Vanuatu, Zâmbia, Zimbabwe

África do Sul, Arábia Saudita, Argentina, Azerbaijão, Baamas, Belarus, Bolívia, Brasil, Bulgária, Cazaquistão, nica, Egito, Eslováquia, Estônia, Filipinas, Grécia, Guatemala, Honduras, Hungria, Índia, Indonésia, Jamaica, Kenia, Látiva, Malásia, Malta, Marrocos, México, Nigéria, Panamá, Paquistão, Peru, Portugal, Quirguistão, Rep. Checa, Rep. Dominicana, Romênia, Rússia, Síria, Sri Lanka, Tailândia, Turquia, Ucrânia, Uruguai, Usbequistão, Venezuela

Fonte: Silva (2003).

Relativamente ao NSI em geral, há um aumento significativo de países pertencentes ao regime I quando apenas o setor saúde é considerado: 47 países não possuem produção científica e/ou tecnológica. Esses países se caracterizam por possuírem sistemas de inovação sem produção sistemática em ciência e/ou tecnologia em saúde, o que indica a precariedade do setor em termos dos indicadores de C\&T ao nível mundial.

Os 54 países do regime II são caracterizados por possuírem sistemas de inovação imaturos e maduros sem ênfase em saúde. Esse grupo é relativamente equilibrado quando comparado ao conjunto de países que integram o regime II para o NSI (52 países). 
TABELA 2

Países componentes do NSI saúde por regime de interação - 2001

\begin{tabular}{|c|c|c|}
\hline Regimes & Países & Países por regime \\
\hline Regime I & $\begin{array}{l}\text { Albânia, Argélia, Armênia, Azerbaiião, Bolívia, Bósnia e } \\
\text { Herzegovina, Camarões, Congo (Rep. Dem.), Congo (Peopl. } \\
\text { Rep.), Emirados Árabes Unidos, Etiópia, Gana, Guiné, Haiti, } \\
\text { Iraque, Jamaica, Lesoto, Líbano, Líbia, Macedônia, Malawi, } \\
\text { Mali, Marrocos, Maurício, Mauritânia, Mongólia, Myanmar, } \\
\text { Namíbia, Nepal, Niger, Omã, Panamá, Paquistão, Paraguai, } \\
\text { Portugal, Quirguistão, Rep. Malagasy, Senegal, Serra Leoa, } \\
\text { Sudão, Tanzânia, Tunísia, Uganda, Uruguai, Usbequistão, } \\
\text { Yemen, Zâmbia }\end{array}$ & 47 \\
\hline Regime II & $\begin{array}{l}\text { África do Sul, Arábia Saudita, Argentina, Belarus, Brasil, } \\
\text { Bulgária, Cazaquistão, Chile, China, Colômbia, Coréia do } \\
\text { Sul, Croacia, Cuba, Egito, El Salvador, Equador, Eslováquia, } \\
\text { Eslovênia, Espanha, Estônia, Filipinas, Grécia, Honduras, } \\
\text { Hungria, Índia, Indonésia, Irã, Irlanda, Itália, Jordânia, Kenia, } \\
\text { Kuwait, Látvia, Lituânia, Malásia, México, Nigéria, Peru, } \\
\text { Polônia, Rep. Checa, Rep. Dominicana, Romênia, Rússia, } \\
\text { Singapura, Sri Lanka, Tailândia, Taiwan, Trindade e Tobago, } \\
\text { Turquia, Ucrânia, Venezuela, Vietnã, Yugoslávia, Zimbabwe }\end{array}$ & 54 \\
\hline Regime III & $\begin{array}{l}\text { Alemanha, Austrália, Áustria, Bélgica, Canadá, Dinamarca, } \\
\text { Estados Unidos, Finlândia, França, Holanda, Israel, Japão, } \\
\text { Noruega, Nova Zelândia, Reino Unido, Suécia, Suiça }\end{array}$ & 17 \\
\hline Total de países & & 118 \\
\hline
\end{tabular}

Fonte: USPTO, ISI, World Bank (elaboração própria).

Finalmente, para os países com sistemas maduros com ênfase em saúde há uma queda na participação, de 27 países pertencentes ao NSI para 17 países pertencentes ao NSI em saúde. Novamente, observa-se que a situação da saúde é delicada, pois, em relação ao NSI, houve redução na quantidade de países que possuem infra-estrutura científica e tecnológica consolidada.

Seguindo a estrutura anterior, a análise de cluster foi também aplicada aos dados de artigos e patentes para a saúde mental. Os principais resultados são apresentados na Tabela 3. 
TABELA 3

Países componentes da saúde mental por regime de interação - 2001

\begin{tabular}{lll}
\hline Regimes $\quad$ Países & Países por regime
\end{tabular}

Regime I

Albânia, Arábia Saudita, Argélia, Armênia, Azerbaijão,

Ao observar os dados acima, dois pontos relativos aos extremos (regimes I e III) merecem destaque. Primeiro, o número de países que compõem o regime I em saúde mental aumenta de forma significativa comparados com os dados da saúde: a quantidade de países sem produção em ciência e/ou tecnologia passa de 47 (saúde) para 85 (saúde mental). Isso significa que vários países que faziam parte do regime II em saúde, entre os quais o Brasil, passam para o regime I, considerado o pior dos três regimes de interação. Segundo, houve estabilidade quanto ao número de países (17) que compõem o regime III tanto em saúde 
como em saúde mental. Porém, ocorreu uma pequena mudança em sua composição: o Japão faz parte do regime III em saúde e do regime II em saúde mental; a Irlanda pertence ao regime II em saúde e ao regime III em saúde mental.

No entanto, deve-se destacar que os dados sobre patentes em saúde mental possuem uma limitação: as atividades científicas geram drogas patenteáveis, mas também novas terapias não patenteáveis. Por isso, uma nova base de dados sobre atenção à saúde mental foi utilizada e uma segunda tipologia de países foi construída, a partir da metodologia GoM (para maiores detalhes, ver Chaves, 2005). Apesar desta limitação das estatísticas de artigos e patentes, ressalta-se que os resultados obtidos com a nova base de dados e metodologia são importantes para validar aqueles obtidos a partir das estatísticas de C\&T e da metodologia de clusters hierárquicos. Em síntese: duas bases de dados são utilizadas, duas metodologias são empregadas e os resultados são consistentes.

Seguindo nomenclatura similar à dos regimes de interação, foram gerados três perfis extremos e seis mistos, assim caracterizados:

- perfil extremo 1: engloba os países com as piores condições de atenção à saúde mental e renda;

- perfil extremo 2: engloba os países com condiçōes intermediárias em termos da atenção à saúde mental e renda;

- perfil extremo 3: engloba os países com as melhores condições de atenção à saúde mental e renda;

- perfis mistos: conforme o nome sugere, os países classificados nesses perfis possuem uma mistura das características dos perfis extremos acima mencionados.

Os resultados da tipologia de países ${ }^{9}$ encontrada a partir do GoM estão sintetizados na Tabela 4.

Aqui cabem duas observações. Em primeiro lugar, todos os países que pertencem ao perfil extremo 1, caracterizado pelas piores condições em termos de atenção à saúde mental, integram o regime I em saúde mental e em saúde geral

\footnotetext{
9 Os clusters são apresentados no anexo, conforme dendogramas 1.Ae 1.B. Para a saúde geral, os países que compõem - cluster 1 englobam de Filipinas a Taiwan e pertencem ao regime II. Os países que estão fora do cluster 1, desde a França aos Estados Unidos, compõem o regime III. Raciocínio análogo, em termos de clusters e regimes de interação, aplica-se à saúde mental em termos de C\&T.
} 
TABELA 4

Tipologia de países com relação a atenção à saúde mental - 2001

\begin{tabular}{lll}
\hline Regimes & Países & Países por regime
\end{tabular}

Perfil extremo 1

Perfil extremo 2

Perfil extremo 3

Perfis mistos
Camarões, Congo (Dem. Rep), Etiópia, Gana, Guiné, Kenia, Malawi, Mali, Mauritânia, Nepal, Niger, Senegal, Serra Leoa, Sudão, Tanzânia, Uganda, Yemen, Zâmbia

África do Sul, Arabia Saudita, Brasil, Chile, China, Colombia, Egito, El Salvador, Em.Árabes Unidos, Irã, Jamaica, Jordânia, Kuwait, Líbia, Maurícius, Omã, Panamá, Paraguai, Peru, Rep. Dominicana, Romênia, Tailândia, Trindade \& Tobago, Tunísia, Turquia, Uruguai, Venezuela

Alemanha, Argentina, Austrália, Áustria, Bélgica, Canadá, Croácia, Dinamarca, Eslováquia, Espanha, Estados Unidos, Finlândia, Grécia, Holanda, Hungria, Israel, Japão, Lituânia, Nova Zelândia, Noruega, Portugal, Reino Unido, Rep.

Checa, Rússia, Suécia, Suíça, Singapura

$$
\begin{aligned}
& \text { Albânia, Argélia, Armênia, Azerbaiião, Belarus, Bolívia, } \\
& \text { Bósnia \& Herceg., Bulgária, Corea do Sul, Cuba, Equador, } \\
& \text { Eslovênia, Estônia, Filipinas, França, Honduras, Índia, } \\
& \text { Indonésia, Iraque, Irlanda, Itália, lugoslávia, Latvia, Lesoto, } \\
& \text { Líbano, Macedônia, Malásia, Marrocos, México, Mongólia, } \\
& \text { Myanmar, Namíbia, Nigéria, Paquistão, Polônia, } \\
& \text { Quirziquistão, Sri Lanka, Ucrânia, Vietnam, Zimbabwe }
\end{aligned}
$$

Fonte: WHO - WMHR, 2001, elaboração própria.

(com exceção de Quênia, que pertence ao regime II em saúde). Em segundo lugar, dos 27 países que compõem o perfil extremo 3, caracterizado pelas melhores condições em termos de atenção à saúde mental, quinze pertencem ao regime III em saúde mental e em saúde geral. Assim, pode-se conjecturar que há um nítido grau de persistência entre os piores e os melhores países do mundo, tanto em termos dos indicadores tradicionais de C\&T quanto em termos dos indicadores de atenção à saúde mental.

Após apresentação de alguns resultados preliminares sobre as tipologias de países, a última seção será dedicada a resumir os principais resultados do trabalho. 


\section{Conclusão}

O objetivo deste artigo foi identificar a posição da saúde mental no interior do sistema de inovação setorial. Muitas foram as singularidades resultantes da comparação entre saúde em geral e saúde mental, o que motivou incluir a discussão sobre saúde mental no interior do arcabouço teórico sobre sistema de inovação setorial em saúde.

Em termos institucionais, o papel das universidades, das instituições de pesquisa e dos hospitais é fundamental para fornecer conhecimento científico ao setor tecnológico. No entanto, a complexidade do conhecimento científico continua sendo a principal barreira ao desenvolvimento tecnológico em saúde e, principalmente, em saúde mental.

Por meio da análise de cluster foi possível investigar quantitativamente as características e distribuiçôes dos países em termos do Sistema Nacional de Inovação - NSI - bem como do NSI em saúde e, assim, estabelecer a tipologia entre os países de acordo com o regime de interação a que pertencem. O ponto central da análise foi determinar um critério para separar os países pertencentes aos regimes II e III. Observam-se mudanças importantes quando o setor saúde é analisado individualmente. De maneira similar ao que ocorre com o NSI, foi detectada a existência de limiar de produção científica para o setor saúde. No entanto, a ausência de interseção entre os dois regimes evidencia uma descontinuidade científico-tecnológica entre ambos. Resultados de trabalhos anteriores mostram que as médias das produções científica e tecnológica do setor saúde crescem significativamente ao se passar do regime II para o regime III, relativamente ao NSI em geral. Esse é o primeiro indicador do nível de exigência imposto aos países do regime II para que ultrapassem o limiar de produção científica e, conseqüentemente, ingresse no regime III. Ao mesmo tempo, sabese que os países do regime III dedicam grande esforço científico ao setor saúde, o que lhes permite gerar uma patente a partir de um número menor de artigos científicos. Esse segundo indicador evidencia maior conexão entre ciência e tecnologia (C\&T) em saúde para os países mais desenvolvidos.

Seguindo linha de argumentação similar, retomou-se a discussão sobre saúde mental e os países foram distribuídos de acordo com o regime de interação a que pertencem. Observou-se que competência na área de saúde mental pres- 
supõe presença em termos de quantidade e ênfase em saúde geral, pois os países do regime III em saúde mental são praticamente os mesmos do regime III em saúde geral. O extremo oposto também foi observado: os países do regime I em saúde mental também pertencem a esse regime em saúde geral. No entanto, com relação aos países que compõem o regime I, os resultados na área da saúde mental são significativamente inferiores aos da saúde geral. A complexidade do conhecimento científico em saúde mental pode ser considerada como uma das principais barreiras a serem superadas para integrar a produção científica e a tecnológica.

Para validar os resultados em saúde mental obtidos pelas estatísticas tradicionais de C\&T (artigos e patentes, respectivamente), uma nova base de dados foi utilizada. Elaborou-se outra tipologia, reagrupando-se países com características semelhantes em termos de política, programa, legislação, tratamento e financiamento em saúde mental. A comparação dos resultados sobre os regimes de interação e perfis extremos é muito interessante. Foi detectada persistência dos países pertencentes ao regime I entre os componentes do perfil extremo 1, caracterizados como os piores do mundo em termos de atenção à saúde mental, e dos países do regime III no perfil extremo 3, caracterizados como os melhores do mundo. Ampliando-se a análise e introduzindo-se o Índice de Desenvolvimento Humano (IDH), observou-se que os países com índices mais baixos pertencem ao regime I e os países com os índices mais elevados pertencem ao regime III.

O Brasil enquadra-se no perfil extremo 2 em saúde mental. Suas principais deficiências referem-se à ausência de instalaçôes/recursos de tratamento para portadores de doenças mentais severas e ausência de treinamento para os trabalhadores da área. Sob o ponto de vista dos profissionais, o País não dispõe da informação sobre o número de neurologistas, neurocirurgiões, enfermeiros psiquiátricos, psicólogos e assistentes sociais per capita. Quanto ao financiamento, foi declarado que 2,5\% do orçamento da saúde é destinado para a saúde mental. Ainda que as conexôes entre C\&T não tenham sido efetivadas, devido a ausência de setores que produzem patentes na área, o país possui potencial científico, pois produz artigos de alta relevância, indexados ao Web of Science.

As principais conclusões a serem tiradas é que o País precisa incentivar a infraestrutura científica em saúde mental para conhecer melhor seu perfil econômico, epidemiológico, demográfico, etc. De posse dessas informações, tor- 
nar-se-ia mais fácil formular estratégias de investimentos para atender as necessidades da população mais carente, localizar as regiōes de maior prevalência e priorizar programas especiais, principalmente para atender aos casos mais graves. É urgente a necessidade de uma política de pessoal, com vistas a fornecer condiçôes e recursos de treinamento para os trabalhadores da área; de mecanismos de financiamento para a saúde mental, já que a parcela do orçamento para esta área é mais baixa que de outros componentes do grupo como por exemplo: Egito (9\%), Jamaica (5\%), Irã (3\%), Romênia (3\%) e África do Sul (2,7\%). Simultaneamente à resolução dessas questões básicas, seria importante promover a sintonia entre C\&T, uma vez que o avanço científico é um guia poderoso para desenvolver a capacidade de absorção de inovações tecnológicas realizadas em países mais avançados, prover conhecimento e atrair o setor produtivo para o país. Desta forma, seria possível incrementar a conexão entre ciência e tecnologia, no sentido de promover a pesquisa e a inovação em torno de medicamentos para distúrbios mentais.

\section{Referências bibliográficas}

Albuquerque, E.M., Apresentação do artigo "The National System of Innovation in Historical Perspective", Revista Brasileira de Inovação, v.3, n.1, p.9-13, jan./jun., Rio de Janeiro, 2004.

Albuquerque, E.M.; Cassiolato, J.E., "As especificidades do sistema de inovação do setor saúde", Revista de Economia Política, v.88, n.4, p.134-151, out./ dez., São Paulo, 2002.

, J.E., As especificidades do sistema de inovação do setor saúde: uma resenha da literatura como introdução a uma discussão sobre o caso brasileiro, São Paulo: FeSBE (Estudos FeSBE I) (www.fesbe.org.br), 2000.

Arrow, K., "Uncertainty and the Welfare Economic of Medical Care, in Arrow, K. (org.) Essays in theory of risk-bearing, p.177-211, Amsterdam; Londres: North Holland, 1971. 
Bernardes, A., Albuquerque, E., "Cross-over, thresholds and interactions between science and technology: lessons for less-developed countries", Research Policy, v.32, n.5, p.865-885, Amsterdam, 2003.

Chaves, C.V., "As interações entre o setor saúde e a saúde mental a partir das estatísticas de ciência e tecnologia”, 139 f., Tese (Doutorado em Economia): Centro de Desenvolvimento e Planejamento Regional, Belo Horizonte: Universidade Federal de Minas Gerais, 2005.

Everitt, B., Cluster analysis, 136p., Nova York: Halstet, 1986.

Freeman, C., “The 'National System of Innovation' in historical perspective”, Cambridge Journal of Economics, v.19, n.1, 1995.

Gelijns, A.C., "Comparing the Development of Drugs, Devices, and Clinical Procedures: appendix A", in Gelijns, A. C. (org.) Modern methods of clinical investigation, p.147-201, Washington: National Academy, 1990. (Medical innovation at the crossroads; 1 )

Griliches, Z., "Patent Statistics as Economic Indicators: a survey", Journal of Economic Literature, v.28, dez., 1990.

Hicks, D.; Katz, J., "Hospitals: the hidden research system", Science and Public Policy, v.23, n.5, p.297-304, out., 1996.

IBGE - Pesquisa industrial - inovação tecnológica 2000: análise dos resultados. Rio de Janeiro: IBGE, 2002.

Kaufman, L.; Rousseeuw, P.J., Finding groups in data: an introduction to cluster analysis, 342 p., Nova York: John Wiley, 1990.

Klevorick, A.K.; Levin, R.C.; Nelson, R.R.; Winter, S.G., "On the Sources and Significance of Inter-industry Differences in Technological Opportunities", Research Policy, v.24, n.2, p.85-205, mar., Amsterdam, 1995.

Nelson, R.R., "On the Uneven Evolution of Human Know-how", Research Policy, Amsterdam, v.32, n.6, p.909-922, 2003.

Observatoire des Sciences et des Techniques. Indicateurs de sciences et de technologies, 2004. Disponível em: http://www.obs-ost.fr/services/a_propos_ost/ base_donnees/nomenclatures.mhtml

Science \& Technologie: indicateurs 2000, Paris: Econômica, 2000. 
Rosenberg, N., "How Exogenous is Sience?", in Rosenberg, N. (org.) Inside the Black Box: technology and economics, p.41-159, Cambridge, MA: Cambridge University, 1982.

"Why do Firms do Basic Research (with their money)?", Research Policy, Amsterdam, v.19, n.2, p.165-174, 1990.

Sandelin, N.; Sarafoglou, N., "Language and scientific publication statistics: a note", Language Problems \& Language Planning, v.28, n.1, p.1-14, 2004. Disponível em: <http://www.handels.gu.se/epc/archive/00003001/01/ gunwpe0109.pdf

Schmoch, U., "Indicators and the relations between science and technology". Scientometrics, v.38, n.1, p.103-116, 1997.

Silva, L., Padrões de interação entre ciência e tecnologia: uma investigação a partir de estatísticas de artigos e patentes, 110 f. Dissertação (Mestrado em Economia). Belo Horizonte: Centro de Desenvolvimento e Planejamento Regional, Universidade Federal de Minas Gerais, 2003.

Simões, R.F., Complexos industriais no espaço: uma análise de fuzzy cluster. Belo Horizonte: UFMG/Cedeplar, 2003. (Texto para Discussão; 209)

United States Patents and Trademark Office, 2002, 2003. Disponível em: http:/ /www.uspto.gov

World Bank. World development report: investing in health, Oxford: Oxford University, 1993.

World Health Organization. Investing in health research and development: report of the ad hoc committee on health research relating to future intervention options. Genebra: WHO, 1996. 278p.

The world health report: mental health, new understanding, new hope. Genebra: WHO, 2001. 178p. Disponível em: http://wwwwho.int/ whr2001/2001/main/en/pdf/index.htm. 


\section{Bibliografia consultada}

Breschi, S.; Malerba, F., "Sectoral innovation systems: technological regimes, schumpeterian dynamics, and spatial boundaries", in Edquist, C. (org.), Systems of innovation: technologies, institutions and organizations, Londres: Pinter, p.130-156, 1997.

Cerqueira, C.A., Tipologia e características dos estabelecimentos escolares brasileiros, 295f. Tese (doutorado em Demografia) - Centro de Desenvolvimento e Planejamento Regional, Belo Horizonte: Universidade Federal de Minas Gerais, 2004.

Chaves, C.V.; Albuquerque, E., Desconexão no sistema de inovação no setor saúde: uma avaliação preliminar do caso brasileiro a partir de estatísticas de patentes e artigos. Belo Horizonte: UFMG/Cedeplar, 2004. 22p. (Texto para Discussão; 236)

Cohen, W.; Nelson, R.; Walsh, J., "Links and impacts: the influence of public R\&D on industrial research", Administration Science, v.48, n.1, p.1-23, 2002.

Freeman, C.: Soete, L., The economics of industrial innovation, Londres: Pinter, 316 p., 1997.

Gelijns, A.; Rosenberg, N., "The changing nature of medical technology development”, in Rosenberg, N.; Gelijns, A.; Dawkins, H., Sources of medical technology: universities and industry, Washington: National Academy, p.3-14, 1995. (Medical Innovation at the Crossroads; 5)

Manly, B.F.J., Multivariate statistical methods: a primer, Nova York: Chapman and Hall, 159 p., 1986.

Manton, G.; Woodbury, M.; Tolley, D., Statistical applications using fuzzy sets, Nova York: John Wiley, 312 p. 1994.

Meyer-Krahmer, F.; Schmoch, U., "Science-based technologies: university-industry interactions in four fields", Research Policy, Amsterdam, v.27, n.8, p.835851, 1998.

Narin, F.; Hamilton, K.S.; Olivastro, D., "The increasing linkage between U.S. technology and public science", Research Policy, Amsterdam, v.26, n.3, p.317330, 1997. 
Nelson, R.R., "The intertwining of public and proprietary in medical technology", in Rosenberg, N., Gelijns, A.; Dawkins, H., Sources of medical technology: universities and industry, Washington: National Academy, p.219-220, 1995. (Medical Innovation at the Crossroads, v.5)

Nelson, R.R.; Rosenberg, N., "Technical innovation and national systems", in Nelson, R.R. (org.) National innovation systems: a comparative analysis, Nova York; Oxford: Oxford University, p.3-21, 1993.

Pavitt, K. "What makes basic research economically useful?", Research Policy, Amsterdam, v.20, n.2, p.109-119, 1991.

Sawyer, D.O.; Fígoli, M.G.B.; Rodrigues, R.N.; Garcia, R.A., "Caracterização dos tipos de doadores de sangue em Belo Horizonte: heterogeneidade do homogêneo", in: Encontro Nacional de Estudos Populacionais, 12, 2000, Caxambu, MG. Brasil 500 anos: mudanças e continuidades; anais. Belo Horizonte: ABEP, 2000. (Disponível em CD-ROM)

Sawyer, D.O.; Leite, I.C.; Alexandrino, R., "Perfis de utilização de serviços de saúde no Brasil", Ciência \& Saúde Coletiva, Rio de Janeiro, v.7, n.4, p.757776, 2002.

Science Citation Index, Institute for Science Information. Web of Science 2002, 2003. Disponível em: http://www.webofscience.com. 
Anexo

TABELA 1.A

Algoritmo de correspondência entre as subclasses da classificação internacional de patentes $(\mathrm{Ompi}$ ) e os domínios e subdomínios tecnológicos propostos pelo Observatoire des Sciences et des Techniques (OST)

\begin{tabular}{|c|c|c|}
\hline $\begin{array}{l}\text { Domínios } \\
\text { tecnológicos (DT-7) }\end{array}$ & $\begin{array}{l}\text { Subdomínios } \\
\text { tecnológicos (DT-30) }\end{array}$ & Classe WIPO \\
\hline $\begin{array}{l}\text { 1- Eletrônica - } \\
\text { eletricidade }\end{array}$ & $\begin{array}{l}\text { 01. Componentes elétricos } \\
\text { 02. Audiovisual } \\
\text { 03. Telecomunicações } \\
\text { 04. Informática } \\
\text { 05. Semicondutores }\end{array}$ & $\begin{array}{l}\text { F2 1; G05F; H01B, C, F, G, H, J, K,M, R, T; H02; H05B, C, F, K } \\
\text { G09F, G;G11B; H03F, G, J; H04N, R, S } \\
\text { G08C; H01P,Q; H03B, C, D, H, K, L, M; H04B, H, J, K, L, M,Q } \\
\text { G06; G11C; G10L } \\
\text { H01L; B81 }\end{array}$ \\
\hline 2 - Instrumentação & $\begin{array}{l}\text { 06. Ótica } \\
\text { 07. Análise-Mensuração-Controle } \\
\text { 08. Engenharia médica } \\
\text { 09. Técnicas nucleares }\end{array}$ & $\begin{array}{l}\text { G02; G03B, C, D, F,G, H; H01S } \\
\text { G01B, C, D, F, G, H, J, K, L, M, N, P, R, S, V, W; } \\
\text { G04; G05B, D; G07; G08B, G; G09B, C, D; G12 } \\
\text { A61B, C, D, F, G, H, J, L, M, N } \\
\text { G01T; G2 1; H05G, H }\end{array}$ \\
\hline $\begin{array}{l}3 \text { - Química - } \\
\text { materiais }\end{array}$ & $\begin{array}{l}\text { 10. Química orgânica } \\
\text { 11. Química macromolecular } \\
\text { 12. Química de base } \\
\text { 13. Tratamento de superfícies } \\
\text { 14. Materiais-metalurgia }\end{array}$ & $\begin{array}{l}\text { C07D, F, G, H, J, K } \\
\text { C08B, F, G, H, K, L; C09D, J } \\
\text { A01N; C05; C07B; C08C; C09B, C, F, G, H, K; } \\
\text { C10B, C, F, G, H, J, K, L, M; C11B, C, D } \\
\text { B05C, D;B32;C23;C25; C30 } \\
\text { C01; C03C;C04;C21; C22;B22, B82 }\end{array}$ \\
\hline $\begin{array}{l}4 \text { - Farmácia e } \\
\text { biotecnologia }\end{array}$ & $\begin{array}{l}\text { 15. Biotecnologia } \\
\text { 16. Farmácia e cosméticos } \\
\text { 17. Produtos agrícolas e } \\
\text { alimentares }\end{array}$ & $\begin{array}{l}C 12 M, N, P, Q, S \\
A 61 K, P \\
A 01 H ; A 21 D ; A 23 B, C, D, F, G, J, K, L ; C 12 C, F, G, H, J ; \\
C 13 D, F, J, K\end{array}$ \\
\hline $\begin{array}{l}5 \text { - Procedimentos } \\
\text { industriais }\end{array}$ & $\begin{array}{l}\text { 18. Procedimentos técnicos } \\
\text { 19. Manutenção-gráfica } \\
\text { 20. Aparelhos agrícolas } \\
\text { e alimentares } \\
\text { 21. Trabalho com materiais } \\
\text { 22. Meio ambiente-polvição }\end{array}$ & $\begin{array}{l}\text { B01; B02C; B03; B04; B05B; B06; B07; B08; F25J; F26 } \\
\text { B25J;B41; B65B, C, D, F, G, H; B66; B67 } \\
\text { A01B, C, D, F, G, J, K, L, M; A2 1B, C; } \\
\text { A22; A23N, P;B02B;C12L; C13C, G, H } \\
\text { D01; D02; D03; D04B, C, G, H; D06B, C, G, H, J, L, M, } \\
\text { P, Q; D21 } \\
\text { A62D;B09; C02; F01N; F23G, J }\end{array}$ \\
\hline $\begin{array}{l}6 \text { - Máquinas - } \\
\text { mecânica - } \\
\text { transportes }\end{array}$ & $\begin{array}{l}\text { 23. Máquinas-ferramenta } \\
\text { 24. Motores-bombas-turbinas } \\
\text { 25. Procedimentos térmicos } \\
\text { 26. Componentes mecânicos } \\
\text { 27. Transportes } \\
\text { 28. Espacial-armamentos }\end{array}$ & $\begin{array}{l}\text { B2 1; B23; B24; B26D, F; B27; B30 } \\
\text { F01 (souf F01N); F02; F03; F04; F23R } \\
\text { F22; F23B, C, D, H, K, L, M, N, Q; F24;F25B, C;F27;F28 } \\
\text { F15; F16; F17; G05G } \\
\text { B60;B61;B62;B63B, C, H, J;B64B, C, D, F } \\
\text { B63G;B64G; C06; F41; F42 }\end{array}$ \\
\hline $\begin{array}{l}7 \text { - Consumo } \\
\text { de famílias e } \\
\text { construção civil }\end{array}$ & 30. Construção civil (BTP) & $\begin{array}{l}\text { A24; A41B, C, D, F, G; A42; A 43B, C; A44; A45; } \\
\text { A46B; A47; A62B, C;A63; B25B, C, D, F, G, H; B26B; } \\
\text { B42;B43;B44;B68; D04D; D06F, N;D07; F25D; G10B, } \\
\text { C, D, F, G, H, K } \\
\text { E01;E02; E03;E04;E05; E06; E21 }\end{array}$ \\
\hline
\end{tabular}

Fonte: OST, p. 513-514, 2004. 
QUADRO 1.A

Disciplinas científicas

Administração; agricultura/agronomia; al, robótica e cont. auto.; anestesiologia; arqueologia; arte e arquitetura; artes; biblioteconomia e ciência da informação; biologia; biologia celular e do desenvolvimento; biologia experimental; biologia molecular e genética; bioquímica e biofísica; biotecnologia e microbiologia aplicada; ciência da computação e engenharia; ciência da saúde e serviços; ciência das plantas; ciência de alimentos/nutrição; ciência dos animais; ciência dos animais e das plantas; ciência dos materiais e engenharia; ciência espacial; ciência política e administração pública; ciências aquáticas; ciências da terra; cirurgia; clínica em psicologia e psiquiatria; clínica geral; clínica imunológica e doenças infecciosas; comunicação; dentística, cirurgia oral e medicina; dermatologia; direito; economia; educação; endocrinologia, metabolismo e nutrição; eng. Aeroespacial; engenharia ambiental/energia; engenharia civil; engenharia elétrica e eletrônica; engenharia matemática; engenharia mecânica; engenharia mgmt/geral; engenharia nuclear; engenharia química; entomologia; espect./instrum./ciên. analit.; estudos ambientais, geol e desenvolvimento; estudos clássicos; farmacologia e farmácia; filosofia; física; física aplicada/mat. cond./ciên. mat.; físico-química; fisiologia; gastroenterologia e hepatologia; geol/petrol/engenharia de minas; hematologia; história; imunologia; instrumentação/medição; línguas; literatura; matemática; medicina ambiental e saúde pública; medicina geral e interna; medicina reprodutiva; medicina veterinária/saúde animal; meio ambiente/ecologia; metalurgia; microbiologia; multidisciplinar; neurociência e comportamento; neurologia; oftalmologia; oncologia; oncologia e pesquisa sobre câncer; ortopedia; ótica; otorrinolaringologia; pediatria; pesq. médica, órgãos e sistemas; pesq./med. lab. e tecnol. médica; pesquisa médica e tópicos gerais; pesquisa médica, diagnóstico e tratamento; psicologia; psiquiatria; química; química agrícola; química e análise; química inorgânica e nuclear; química orgânica; radiologia, medicina nuclear e imagens; reabilitação; religião e teologia; reumatologia; saúde pública e ciência da saúde; serviço social e política social; sistema cardiovascular e pesquisa em hematologia; sistema cardiovascular e respiratório; sociologia e antropologia; tecnologia da informação e comunicação; toxicologia; urologia.

Fonte: ISI, 2004.

${ }^{1}$ As disciplinas relacionadas em negrito são relacionadas ao setor saúde. 
DENDOGRAMA 1.A

Artigos per capita $\left(\mathrm{A}^{*}\right)$ e patentes per capita $\left(\mathrm{P}^{*}\right)$ para saúde geral países pertencentes aos regimes II e III - 2001

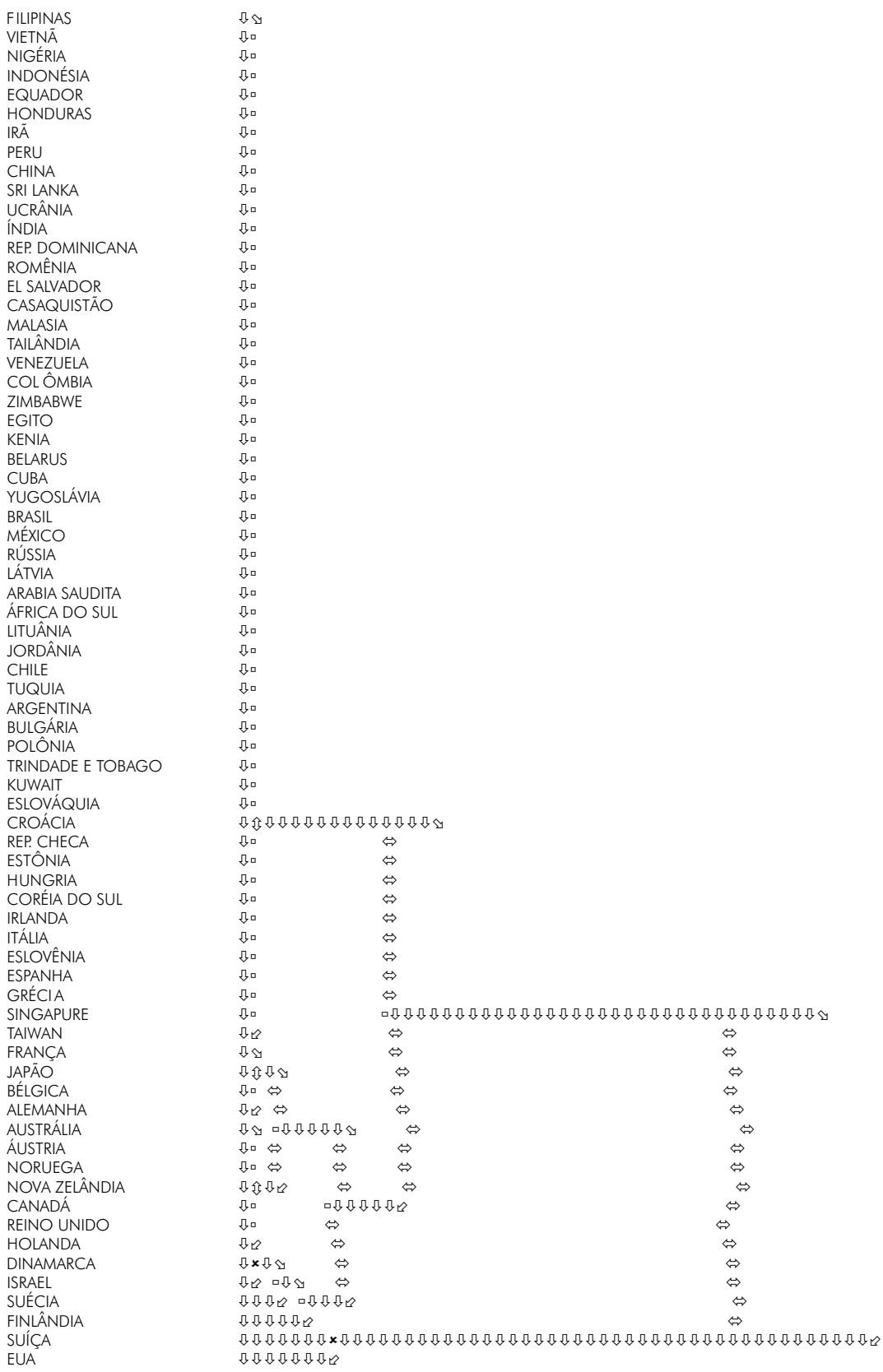

Fonte: ISI, USPTO, 2003, elaboração própria. 
DENDOGRAMA 1.B

Artigos per capita $\left(\mathrm{A}^{*}\right)$ e patentes per capita $\left(\mathrm{P}^{*}\right)$ para saúde mental países pertencentes aos regimes II e III - 2001

\begin{tabular}{|c|c|c|c|}
\hline CHINA & \multicolumn{3}{|l|}{ 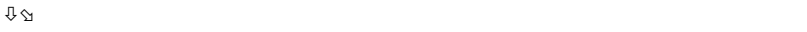 } \\
\hline ÍNDIA & \multicolumn{3}{|l|}{ תुa } \\
\hline ARGENTINA & \multicolumn{3}{|l|}{$\sqrt{\mathrm{N}} \mathrm{a}$} \\
\hline ÁFRICA DO SUL & \multicolumn{3}{|l|}{$\sqrt{30}$} \\
\hline MÉXICO & \multicolumn{3}{|l|}{$\sqrt{30}$} \\
\hline YUGOSLÁVIA & \multicolumn{3}{|l|}{ 约 } \\
\hline POLÔNIA & \multicolumn{3}{|l|}{$\sqrt{\mathrm{a}}$} \\
\hline CROÁCIA & \multicolumn{3}{|l|}{$\sqrt{\mathrm{n}} \mathrm{a}$} \\
\hline REP. CHECA & \multicolumn{3}{|l|}{$\sqrt{\mathrm{a}}$} \\
\hline CORÉIA DO SUL & \multicolumn{3}{|l|}{$\sqrt{3}$} \\
\hline ESLOVÊNIA & \multicolumn{3}{|l|}{ Љ企岛 } \\
\hline TAIWAN & \multicolumn{3}{|l|}{$\sqrt{\Omega} \square \Leftrightarrow$} \\
\hline HUNGRIA & \multicolumn{3}{|l|}{$\sqrt{0} 0 \Leftrightarrow$} \\
\hline ESPANHA & \\
\hline JAPÃO & \multicolumn{3}{|c|}{ 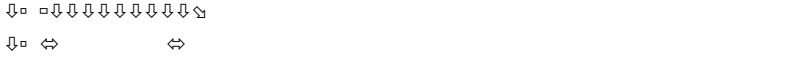 } \\
\hline ITÁLIA & $\sqrt{\square} \Leftrightarrow$ & \multicolumn{2}{|l|}{$\Leftrightarrow$} \\
\hline ÁUSTRIA & $\sqrt{ } \circlearrowleft \Leftrightarrow$ & \multicolumn{2}{|l|}{$\Leftrightarrow$} \\
\hline BÉLGICA & 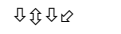 & \multicolumn{2}{|l|}{$\Leftrightarrow$} \\
\hline ALEMANHA & תु० & \multicolumn{2}{|l|}{$\Leftrightarrow$} \\
\hline IRLANDA & תु० & \multicolumn{2}{|c|}{ 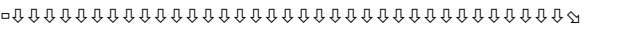 } \\
\hline FRANÇA & $\sqrt{8}$ & $\Leftrightarrow$ & $\Leftrightarrow$ \\
\hline AUSTRÁLIA & $\sqrt{ } \unlhd$ & $\Leftrightarrow$ & $\Leftrightarrow$ \\
\hline NOVA ZELÂNDIA & תูం & $\Leftrightarrow$ & $\Leftrightarrow$ \\
\hline NORUEGA & 约岛 & $\Leftrightarrow$ & $\Leftrightarrow$ \\
\hline CANADÁ & Лூロ ロЉูऽ & $\Leftrightarrow$ & $\Leftrightarrow$ \\
\hline HOLANDA & $\sqrt{\Omega} \Leftrightarrow \Leftrightarrow$ & $\Leftrightarrow$ & $\Leftrightarrow$ \\
\hline FINLÂNDIA & Лூூタロ 吸 & オூタタロ & $\Leftrightarrow$ \\
\hline REINO UNIDO & $\sqrt{ } \times \sqrt{ } \Leftrightarrow$ & & $\Leftrightarrow$ \\
\hline EUA & クロロクロ & & $\Leftrightarrow$ \\
\hline ISRAEL & $\sqrt{ } \unlhd \Leftrightarrow$ & & $\Leftrightarrow$ \\
\hline SuÍÇA & Л众凤曰 & & $\Leftrightarrow$ \\
\hline SUÉCIA & $\sqrt[3]{ }$ & & $\Leftrightarrow$ \\
\hline DINAMARCA & 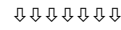 & 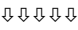 & 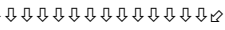 \\
\hline
\end{tabular}

Fonte: ISI, USPTO, elaboração própria. 